\title{
Study on Profile Characteristics of Self-help Group members in Himachal Pradesh
}

\author{
Surinder Singh ${ }^{1^{*}}$ and B.S. Hansra ${ }^{2}$ \\ ${ }^{1}$ School of Agriculture, Indira Gandhi National Open University, New Delhi, India \\ ${ }^{2}$ Amity International University, Noida, Uttar Pradesh, India \\ *Corresponding author: singhsurin@yahoo.com (ORCID ID: 0000-0002-7451-3437)
}

Paper No. 903

Received: 14-02-2021

Revised: 20-04-2021

Accepted: 27-05-2021

\begin{abstract}
Self-help groups have emerged as a vital tool for economic development in India. In hill states like Himachal Pradesh importance of self-help group increases manifold due to higher number of fragmented small and marginal landholdings. Self-help groups must sustain as an economic venture for the overall development of rural areas. It is very important to study individual member traits to understand the sustainability of self-help groups. The present study was conducted in the state of Himachal Pradesh to assess socio-personal, socio-economic, and communication variables of self-help group members and to make a comparison with non-member farmers. Findings of the study reveal that most of the SHG members were of the middle age category, with dominating membership by women farmers. Most of the SHG members adopted vegetable farming along with other agriculture activities with medium vegetable growing experience. SHG members attended significantly higher training programmes than non-member farmers. Most of the farmers have marginal landholding but SHG members put a significantly higher portion of landholding in vegetable cultivation when compared to non-member farmers. Significantly higher vegetable production was reported for SHG member vegetable farms, and the reason for this was higher media exposure and significantly higher extension contacts of SHG members than non-members.

\section{HIGHLIGHTS}

(0 Vegetable farming self-help groups have gained momentum during one decade and are important rural economy drivers.

( Sustainability of vegetable farming self-help groups requires an extensive socio-personal, socioeconomic, and communication profile study of SHG members.

(0 Younger and middle-aged farmers are more inclined towards the formation of self-help groups.

o Organizing small and marginal vegetable growers in hills helps to strengthen the rural economy. Women farmers constitute a major portion of self-help group activities.
\end{abstract}

Keywords: Self-help group, profile, vegetable farming, Himachal Pradesh

Fragmented small and marginal landholdings in hill state like Himachal Pradesh has always posed challenges in sustainability of agriculture. 90 percent of the total population resides in rural areas. 71.41 percent of farming families have small and marginal landholdings (GoHP 2021), and it is very difficult to earn a livelihood from these landholdings. Poverty and unemployment are major problems faced by rural communities (Singh and Hansra 2017). Vegetable farming has paved a new path of economic development in a hilly state like Himachal Pradesh. Now farmers are capable of harvesting more monetary value per unit of land (Singh and Hansra 2018). Multiple cropping systems offer special advantages and reduce the probability of low income for small and marginal farmers.

How to cite this article: Singh, S. and Hansra, B.S. 2021. Study on Profile Characteristics of Self-help Group members in Himachal Pradesh. IJAEB, 14(2): 223-228.

Source of Support: None; Conflict of Interest: None 
Vegetables play a vital role on the food front as they are the cheapest- sources of natural foods and can admirably supplement the main cereals of the country (Kumar and Negi 2015). The state has inherent constraints in farming like fragmented land holdings, poor road, and connectivity, lack of irrigation facilities, animal menace, and lack of markets etc. Self-help groups have provided a good environment for the upliftment of socio-economic conditions of rural poor women (Manikonda 2014). It has been very well established that providing finance to the poor after organizing them into homogenous group commonly known as SHGs have given statutory results in India and other developing countries, especially among the rural poor women (Bariya et al. 2017). Non-member farmers perceive higher constraints in vegetable cultivation than SHG member farmers (Singh and Hansra 2021). Self-help groups are collective efforts of the farming community where rural people join together to resolve day-to-day constraints faced in vegetable cultivation. Besides this, development agencies also found it easy and feasible to approach groups rather than to attend individual farmers in remote areas. The benefits of group dynamics help farmers to solve problems and make it easy for the development agencies to reach the farming community. Sustainability of self-help groups for farming community can be best understood by studying the individual SHG members and non-members, farmers. Significant difference in the mean values of SHG members and Non SHG members in case of education, family size, social participation, land holding, annual income, material possession, source of information, extension participation, achievement motivation, market orientation, risk orientation, innovativeness and attitude towards SHGs was reported by Bariya et al. (2017). Out of eight personal profile used for study, marital status and extension contact were found positive and significant, while the education, type of family, annual income, social participation were found positive and highly significant relationship with process empowerment (Deshmukh and Naik 2017). Shree et al. (2016) reported majority (54.78\%) of the SHG members belonged to middle age group. More than one third of the respondents (36.24\%) belonged to low education category, 98.77 per cent had low organizational status, 36.13 per cent were wage earners and 47.18 per cent had joined SHGs to get loans. Study conducted by Wankhade et al. (2011) also revealed that nearly fifty per cent of the respondents of self help groups belonged to young age group, nearly one-third of the women were educated up to college level, majority of them belonged to open category followed by OBC category. The higher proportions of women respondents were married and nearly two-third of respondents had medium family size having over half of them belonged to nuclear type of family system. Similarly study conducted by Tejaswini and Panigrahi (2021) also revealed that $50 \%$ of the respondents belonged to middle age group, 55.83\% of women SHG members received high school education, $49.16 \%$ of respondents belonged to small farmer category having land up to 1 acre. The study revealed that majority i.e., $81.66 \%$ of respondents belong to joint family category and $55 \%$ respondents cited agriculture as their occupation. Although lot of research has been done on studying profie of self-help group members but very limited research is available for farmers practicing agriculture in hilly regions. Keeping in view the problem of less availability of data on individual vegetable farmers profile in the hilly states, the present study was conducted with the following objectives:

1. To assess profile characteristics of vegetable growing self-help group members and nonmembers farmers.

2. Comparative study of various socio-personal, socio-economic, and communication variable for SHG member and non-SHG member farmer

\section{MATERIALS AND METHODS}

The study was conducted in the state of Himachal Pradesh, covering all three divisions to cover all agro-climatic zones of the state. From each division, two districts were randomly selected, and from the exhausted list of vegetable growing self-help groups, five self-help groups were selected in each district, thus covering a total of 30 self-help groups from the state. From each selected group, 5 members were selected randomly to collect data, and 150 self-help group member farmers were included in the study. To make comparison 150 Non-member farmers from the adjacent villages were selected randomly. So, the sample size for the proposed study was 300 (150 group members and150 non-member). 
Selected SHG members and non-members were directly interviewed using a pre-tested structured schedule. The finding was tabulated, analyzed using appropriate statistical techniques, and presented in different groups like socio-personal, socio-economic, and communication variables

\section{RESULTS AND DISCUSSION}

1. Age: Physical and psychological development is related to age which influences the interest and needs of an individual and also affects future goals and expectations. It is evident from Table 1 that indicates that the majority of members (43.33 percent) were middle age group followed by young age (32.67 percent). For non-members majority of the respondents were middle-aged followed by old age. Thus it is found that middle-age, and young age farmers were more interested in self-help group formation.

2. Gender: Gender of farmers is helpful in studying the gender orientation of community towards group problem-solving at village level. It is evident from the study (Table 1) that women farmers are more oriented towards self-help group formation than male farmers as 130 (86.67 percent) SHG members were reported, female farmers.

3. Education: Education is an act or process of acquiring general knowledge, developing the process of reasoning and judgment, and preparing oneself for mature life. The education status of an individual farmer plays a vital role in realizing higher performance through a better understanding of the mechanism involved in the formation and functioning of SHGs and practicing scientific vegetable farming. Table 1 indicates that the majority of the members (26.67 per cent) were having a secondary level of education, followed by middle education status (21.33 percent). In the case of non-members majority of the respondents were functional literate (28.67 percent) followed by middle level (26.67 percent) of education. It is also revealed from the Table 1 that with an increase in education farmer tends to be a member of SHGs.

4. Occupation: Occupation status indicates the type of income-generating activities undertaken by the respondent and decides the extent of involvement of the farmer in the farm operations. The occupation of the respondents is presented in Table 1 . The table reveals that the majority of the respondent farmers from members (52.67 percent), as well as non-members (62.67 percent), were practicing mixed agriculture i.e., vegetable farming plus other agricultural activities, followed by vegetable farming plus business/service by a member (28.00 percent) and non-members(25.33 percent). Vegetable farming as a sole activity was undertaken only by 19.33 percent of member and 12.00 percent nonmember farmers.

5. Years of experience in vegetable farming: Farming experience is valuable in building successful livelihood and fosters the ability to assume greater responsibility. It also influences the knowledge and adoption behavior, including the rejection of an innovation. Table 1 reveals that the majority of the members (67.33 percent), as well as non-members (76.00 per cent), were having short vegetable farming experience, followed by 20.67 percent members and 13.33 percent members in medium experience category respectively. Long experience (above 14 years) was confined to 12.00 percent members and 10.67 percent non-members.

6. Loan received: The idea behind the formation of SHG is to provide financial services to those who remain out of the reach of institutional financial services. Table 1 loan received by the respondents. A perusal of the Table 1 reveals that majority of the respondents (52.00 percent) has received bank loan whereas only 16.00 percent of the non-members have taken loan from banks. The study reveals that the SHG program is successful in providing a platform to the members to reach financial institutions which otherwise remained out of the reach of farmers.

7. Training received: Training is an important activity aimed at imparting knowledge and skill to change attributes and behavior to enhance the performance of the trainees. Training is an activity leading to skill behavior. A close look table 1 reveals that the majority of the members (48.67 percent) received medium training in vegetable farming, whereas the majority of the non-member farmers (36.00 percent) received no training. 26.00 percent of the members found undergone high training (26.00 percent), which was only 4.00 percent for non -members. SHG members significantly received a higher number of training as compared to nonmembers who might be due to the group approach, which is easy to attend by the change agents too. 
Table 1: Distribution of respondents as per socio-personal, socio-economic and communication variables

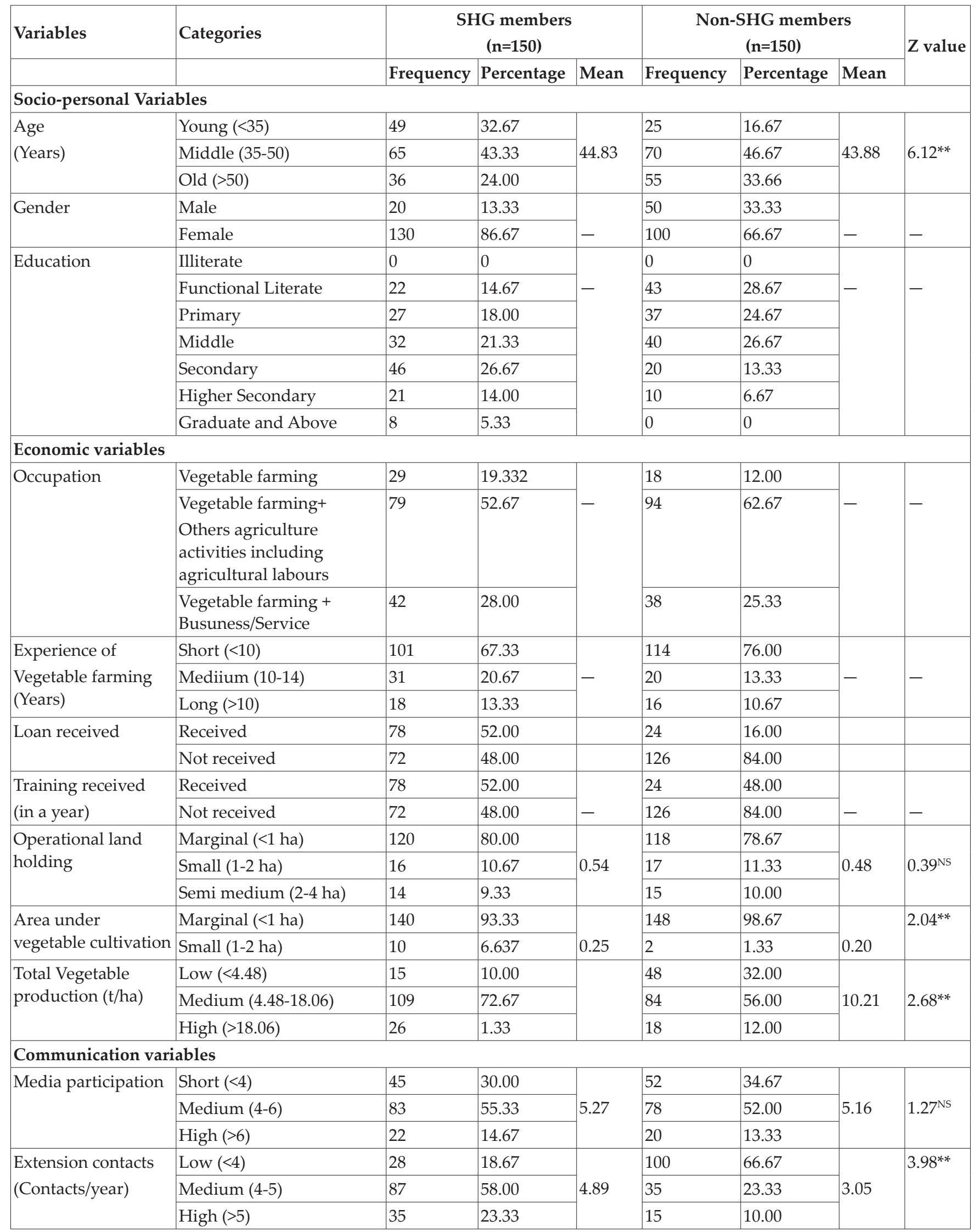

**Significant at 1 percent, NSNon significant. 
8. Operational land holding: Land is one of the important resources of the farmers. Large size of land helps the farmers to take a risk in the adoption of new technologies at their farms. Table 1 revealed that the majority of the members, as well as nonmembers, belong to the marginal landholding category possessed less than one hectare of land, followed by small and semi-medium group.

9. Area under vegetable cultivation: All operational land holding of the farmer is not put into vegetable cultivation, but a portion of suitable land is put into vegetable farming. Information regarding effective area under vegetable cultivation is presented in Table 1 reveals that the majority of the member (93.33 percent), as well as non member (98.67 percent) farmers, but less than one-hectare area under vegetable cultivation but the mean value for members was significantly higher than that of nonmembers at five percent level of probability. The possible explanation for this phenomenon might be group activity that enhances risk-taking ability of the members along with the availability of shortterm loan from SHG.

10. Vegetable production: Table 1 depicts the annual vegetable production in vegetable farms of the respondents. A perusal of the data in the table reveals that the majority of the members' farms (72.67 percent) were in the medium vegetable production category followed by high vegetable production (17.33 percent) whereas the majority of the non-members farms were in medium vegetable production category (56.00 percent) followed by low vegetable production (32.00 percent) category. Vegetable production of SHG member farms was significantly higher than non-members, which proves that organizing vegetable farming farmers into SHGs can boost vegetable production in the state.

11. Media exposure: Exposure to various media helps a farmer to acquire information on vegetable farming, market information, and policies of the government. Exposure to media indicates the degree of progressiveness of the farmers. Data presented in Table 1 revealed that 30.00 percent of the members had fewer media exposure while the corresponding figure for non-members was 34.67 percent. 14.67 percent of members and 13.33 percent of non-member have high media exposure. Majority of the members, as well as non-member, lies in the medium category of media exposure.

12. Extension contacts: Prompt and effective transfer of technologies takes place through the regular extension contact of the farmers with various change agents. Change agent's frequent contact motivates the farmers to adopt new and improved farming practices and also ensures participation of the farmers in decision-making activities. It was found that the majority of the members (58.00 percent) were having medium extension contacts, whereas the majority of non-members were found to have low extension contacts. The difference between member and non-members extension contact was found significant at one percent level of probability which might be due to the fact that SHG members were in regular contact with the various extension workers like the agriculture department, KVKs, banks, etc.

\section{CONCLUSION}

Self-help group intervention in hill vegetable farming can play a pivotal role in economic development and sustainability. The sustainability of self-help groups can be best understood by profile characteristics study of individual members. A comparison of socio-personal, socio-economic, and communication profile variables of self-help group members to that with non-SHG members in the present study proves that participation of comparatively young generation in SHG formation; female farmers are more inclined towards SHG activities. Putting a significantly higher portion of operational land holding and higher vegetable production of SHG member farms clearly proves that SHG formation has great potential in earning sustainable livelihood through vegetable cultivation from small and marginal landholdings in the hill state like Himachal Pradesh. SHG members being in collective action are easy to assess by development agencies as significantly higher extension contacts, and training received were found in the case of SHG members. As a policy intervention, more farmers need to be covered under SHGs for sustaining the agricultural economy in the hills.

\section{REFERENCES}

Bariya, M.K., Chhodvadia, H C., Patel, H., Parmar, S. and Vyas, J. 2017. Study on Proile Characteristics of Women Self-Help Group Members. J. Krishi Vigyan, 5(2): 154-159. 
Deshmukh, D. and Naik, R.M. 2017. Relationship Between Personal Profile and Environment of Rural Women Through SHGs. Guj. J. Ext. Edu., 28(1).

Government of Himachal Pradesh. 2021. Economic Survey. Saving Lives and Livelihood. 2020-21. https:// himachalservices.nic.in/economics/en-IN/economicsurvey.html. Last access date $13^{\text {th }}$ May 2021

Kumar, A. and Negi, S.C. 2015. Crop Diversification for Increasing Productivity and Profitability under Mid-hill Sub-humid Conditions of Himachal Pradesh. Int. J Agri Environ. Biotechnol., 8(4): 861-865.

Manikonda, R. 2014. Socio-economic Profile of the Self-Help Group Women in Andhra Pradesh. Indian Streams Res. J., 4(8).

Singh, S. and Hansra, B.S. 2021. Minimizing Vegetable Production Constraints in Hills: Boon to Attain Sustainable Vegetable Farming System. Indian J. Ext. Educ., 57(1): 5255 .
Singh, S. and Hansra, B.S. 2018. A Study on Environmental Sustainability Index of Vegetable Farming in Himachal Pradesh. Int. J. Agric. Environ. Biotechnol., 11(5): 713-717.

Singh, S., Raman, N.L.M. and Hansra. B.S. 2017. Perspectives of Agritourism in Himachal Pradesh: A New Dimension in Hill Agricultural Diversification. J. Community Mobiliz. Sustain. Dev., 12(2): 207-215.

Shree, D.A., Chandavari, V. and Rayanagoudar, R. 2016. A Study on the Profile of SHGs and their Members in Karnataka. Agric. Int., 3(2): 97-101.

Tejaswini, M. and Panigrahi, R.S. 2021. Socio-Economic Profile of Self-Help Group (SHG) members-A Study in Anantapur District of Andhra Pradesh. Ind. J. Pure App. Biosci., 9(1): 495-500.

Wankhade, P.P., Katole, R.J., Godase, S.K. and Mankar, D.M. 2011. Socio-economic Profile of Women Members in SelfHelp Group. J. Agric. Res. Tech., 3: 443-446. 